\title{
Degenerative tendoachilles tear repaired and augumented by peroneous brevis tendon by dynamic loop technique one year follow up
}

\author{
K. Vijaya Bhaskar Reddy, Narsimha Lavudi*
}

Department of Orthopeadics, MNR Medical College and Hospital, Sangareddy, Telangana, India

Received: 25 February 2020

Revised: 16 June 2020

Accepted: 17 June 2020

\section{*Correspondence:}

Dr. Narsimha Lavudi,

E-mail: narsimhalavudi222@gmail.com

Copyright: (C) the author(s), publisher and licensee Medip Academy. This is an open-access article distributed under the terms of the Creative Commons Attribution Non-Commercial License, which permits unrestricted non-commercial use, distribution, and reproduction in any medium, provided the original work is properly cited.

\section{ABSTRACT}

Background: Repair of degenerative rupture of tendoachilles is a challenge for orthopaedician. We used peroneus brevis tendon in our patients to augment the repair of degenerated tendoachilles tears by creating a dynamic loop.

Methods: In our study, we evaluated 31 patients with Achilles tendon rupture treated by reconstruction using peroneus brevis tendon transfer by dynamic loop suture technique. The patients were from all age groups excluding those lesser than 35 years. The average follow-up being 6 months.

Results: In total 31 patient's majority of patients belong to $41-50$ years (15 cases $48.4 \%$ ). Male patients being 24 $(77.4 \%)$ constituted the majority, right sided injury was noted in $23(74.2 \%)$ of the patients. Most common symptom of Achilles tendon rupture is pain. The mechanism of injury in most of the patients by stumbling in the fields in $19(61.3 \%)$. Results of testing the patient's ability to heel raise for 60 seconds 20 patients were able to sustain, while 8 patients were able to stand on toe with heel raised but could not sustain it. 3 patients could not do raise the heel. 5 patients complained of sensory hypoesthesia at 12 months follow-up. By Rupp scoring, 77\% patients had excellent or good results and 10\% had fair or poor results.

Conclusions: Results of reconstruction of Achilles tendon ruptures using peroneus brevis tendon show a strong and stable repair that allows early weightbearing ambulation with favourable clinical results in most patients.

Keywords: Tendoachilles, Peroneus brevis tendon, Dynamic loop suture technique

\section{INTRODUCTION}

The Achilles tendon is one of the most commonly injured tendons in the human body and is the most often ruptured tendon. The Achilles tendon is the most frequently injured tendons as a result of overuse. Rupture of the Achilles tendon is being reported more frequently in the literature, possibly secondary to a true increase in incidence with greater participation of the general population in physical activities, or because of an increased awareness of the problem. ${ }^{1}$

Despite numerous published studies describing its blood supply, there has been no uniformity in blood supply of
Achilles tendon, it is at highest risk of rupture and surgical complications at its midsection. Individuals with particularly poor supply of the midsection may be at increased risk of tendon rupture, degeneration of the Achilles tendon, surgical complications and delayed repair. $^{2}$

Treatment options for the ruptured Achilles tendon can be classified broadly as operative and nonoperative. Operative treatments can be subdivided into percutaneous and open procedures. Despite developments in operative techniques and biomaterials, the best method of treatment is still debated fiercely. For the last 20 years, open repair has been the procedure of choice for younger, active 
patients and patients with chronic rupture that require reconstructive procedures. The advantages of surgical treatment are the low incidence of re-ruptures and the stronger tendon; disadvantages are the high rate of complications such as infection, delayed healing, adhesions, and reduced ankle joint mobility. 3,4

The Achilles tendon has no true synovial sheath, unlike the flexor tendons of the hand; rather, it is covered only by a paratenon and exogenous healing (from synovial fluid) is not expected to occur. In the past, we initially treated this injury with end suturing and a plaster cast, but this was associated with high rates of re-ruptures and weakened push off. Hence, there is rationale to perform reconstruction using an expendable yet healthy tendon such as the peroneus brevis. The present study was undertaken to elucidate the effectiveness of operative management of ruptured Achilles tendon by reconstructing it with peroneus brevis tendon transfer.

\section{METHODS}

The present prospective study comprised of 31 patients of either sex having ruptured Achilles tendon diagnosed by orthopediacian attended OPD or emergency and were primarily treated by surgical means between august 2017 and December 2019. Total 31 patients under went Dynamic loop suture technique for ruptured Achilles tendon. Study took place in Department of Orthopeadics at MNR Medical College and Hospital from which ethical clearance and patient consent was obtained.

\section{Inclusion criteria}

Inclusion criteria were patients with ruptured Tendo Achilles due to indirect violence both fresh and old above 30 years of age, clinical presentation typical with pain and a snapping sensation behind the ankle following a sudden jerk while engaging in sports or similar activity and weakness with 1 month. The patients complained of difficulty in walking, heel raising and inability to run.

\section{Exclusion criteria}

Exclusion criteria were prior history of surgery for the correction of ruptured Achilles tendon, all ruptures below 30 years of age, compound injuries, ruptures associated with rheumatoid arthritis, immunocompromised, patients using steroids for asthma, chronic renal conditions, history of intralesional injection in tendoachilis region.

Written consent for surgery after explaining delayed wound healing, chances of re-rupture, infection prolonged duration of cast application upto 8 weeks explained.

All the patients presented acutely or within a few days due to inability to walk normally post-injury. Clinical examination revealed local site tenderness, inability to actively plantarflex the ankle (passive plantarflexion was possible) and positive Thompsons' test.

\section{Operative procedure}

Through a postro-lateral longitudinal incision, tendo Achilles and the calcaneal tuberosity were exposed. In the proximal part of the wound the sural nerve was identified and retracted. The peroneus brevis tendon was detached from its insertion through a small incision at the base of the fifth metatarsal.

The aponeurotic septum, was excised separating the lateral and posterior compartments, and the freed peroneus brevis was now delivered into the first incision. A drill hole which was large enough for the passage of the peroneus brevis tendon was made through the transverse diameter of the calcaneal tuberosity. Then the peroneus brevis tendon was passed through this hole and back proximally beside the Achilles tendon, reinforcing the site of rupture, and it was sutured to the peroneus Brevis tendon itself, producing a dynamic loop.

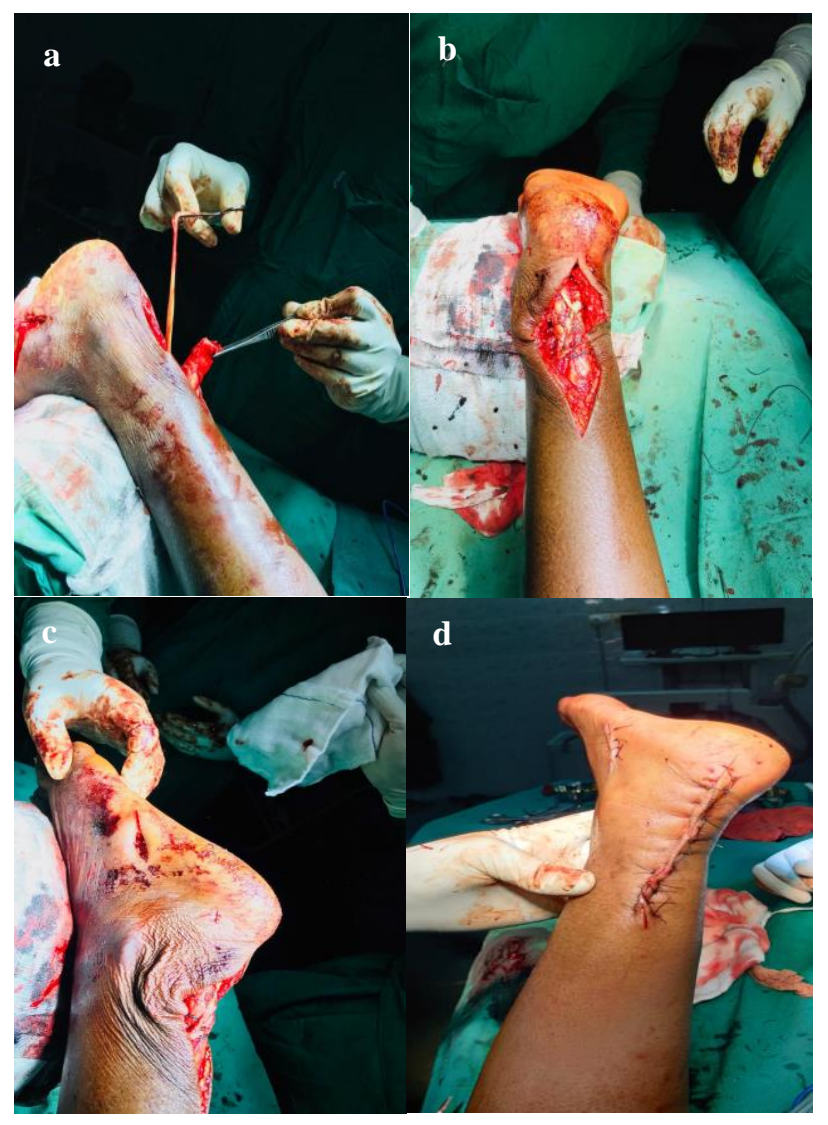

Figure 1 (a-d): Peroneus brevis tendon transfer dynamic loop suture technique for acute tendon rupture.

The cast is removed at 2 weeks, the wound is inspected, and the staples or sutures are removed unless subcuticular sutures were used for wound closure. Cast was changes after 4 weeks. Mobilization of toes and knee advised. Dressing and removal of drain is performed on second post-operative day and slab reapplied. Clinical examination done after six weeks and slab is removed. 
After removal of slab passive and active dorsiflexion and plantar flexion movements of ankle practiced and weight bearing allowed with walker. Patient is allowed to walk with full weight bearing gradually. Standard dynamometer and compared to opposite normal limb at 3 months, 6 months and one year as time permitted in my curriculum. Subjective criteria included the Rupp score, as modified by Kerkhoffs et al. ${ }^{5}$ In addition to information gathered in the follow-up interview, information was also gathered from the patients' medical record.

Data entry was done using M.S. excel and it was statistically analysed using statistical package for social sciences (SPSS version 20) for M.S. windows. Descriptive statistical analysis was carried out to explore the distribution of several categorical and quantitative variables. Categorical variables were summarized with $n$ (\%), while quantitative variables were summarized by mean \pm S.D. All results were also presented in tabular form and are also shown graphically using bar diagram or pie diagram as appropriate.

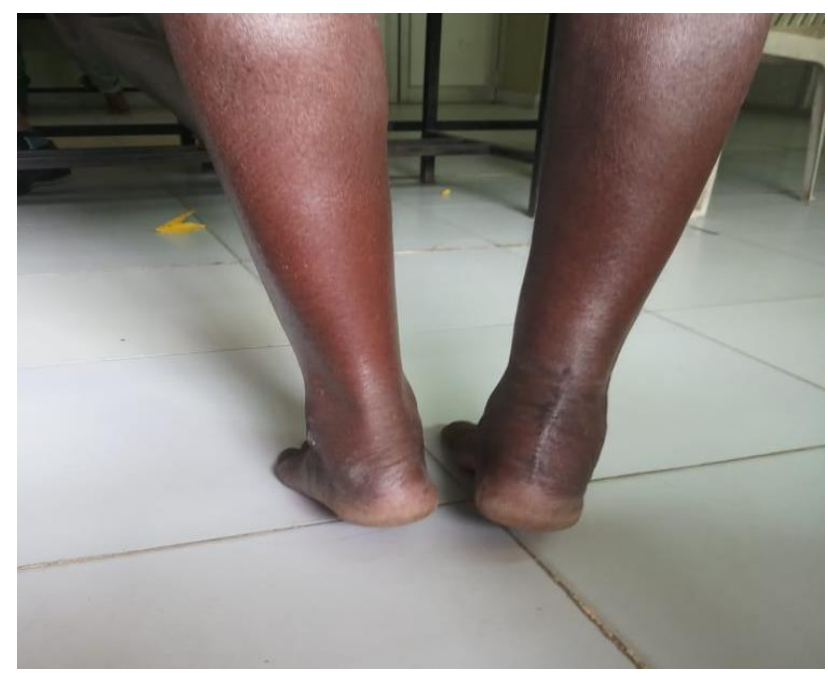

Figure 2: Heel rise with standing on toe after postoperative.

\section{RESULTS}

In our study, we evaluated 31 patients with Achilles tendon rupture treated by reconstruction using peroneus brevis tendon transfer. The patients were from all age groups excluding those lesser than 35 years. The average followup being 6 months.

Majority of patients belong to 41-50 years (15 cases $48.4 \%$ ) followed by $51-60$ years ( 11 cases $35.5 \%)$. Male patients being $24(77.4 \%)$ constituted the majority, with female patients being 7 (22.6\%). Right sided injury was noted in $23(74.2 \%)$ of the patients and left sided in 8 (25.8\%). Most common presentation of Achilles tendon rupture is chronic pain on retrocalcaneal region followed by sudden exaggregation of pain associated with weakness.
Table 1: Demographic details of patients in study.

\begin{tabular}{|c|c|c|}
\hline Demographic & $\begin{array}{l}\text { Number of } \\
\text { patients }\end{array}$ & Percentage \\
\hline \multicolumn{3}{|c|}{ Age intervals (in years) } \\
\hline $35-40$ & 3 & 9.7 \\
\hline $41-50$ & 15 & 48.4 \\
\hline $51-60$ & 11 & 35.5 \\
\hline$>60$ & 2 & 6.4 \\
\hline Total & 31 & 100 \\
\hline \multicolumn{3}{|l|}{ Gender } \\
\hline Male & 24 & 77.4 \\
\hline Female & 7 & 22.6 \\
\hline \multicolumn{3}{|l|}{ Side of injury } \\
\hline Right & 23 & 74.2 \\
\hline Left & 8 & 25.8 \\
\hline \multicolumn{3}{|l|}{ Symptoms } \\
\hline Chronic pain & 28 & 90.3 \\
\hline Weakness & 26 & 83.8 \\
\hline Difficulty on walking & 12 & 38.7 \\
\hline Gap palpable & 30 & 96.7 \\
\hline
\end{tabular}

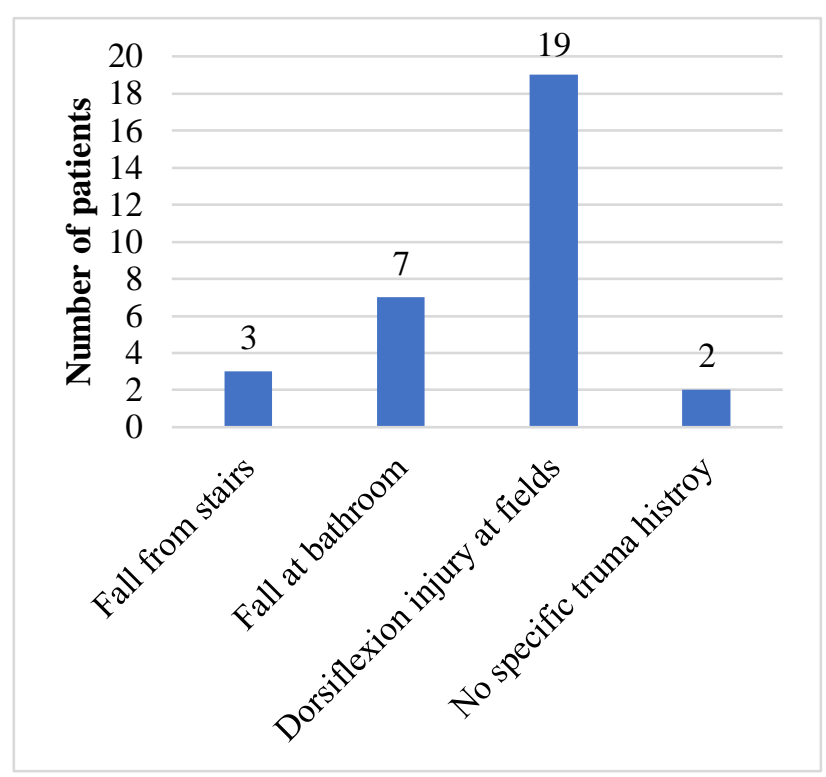

Figure 3: Mechanism of injury in patients of present study.

The mechanism of injury was fallen from stairs in 3 $(9.7 \%)$, fall at home in bathroom $7(22.6 \%)$ patients, stumbling in the fields in $19(61.3 \%)$ and no history of specific trauma prior to the onset of symptoms.

Average dorsiflexion was $18^{\circ}$ (compared to $24^{\circ}$ on the noninjured side) and average plantarflexion was $25^{\circ}$ compared to $36^{\circ}$ on the non-injured side. Results of testing the patient's ability to heel raise for 60 seconds, 20 patients were able to sustain, while 8 patients were able to stand on toe with heel raised but could not sustain it. 3 patients could not do raise the heel. 5 patients complained of sensory hypoesthesia at 12 months follow-up. 
Table 2: Objective measure of follow up.

\begin{tabular}{|lll|}
\hline Objective criteria & $\begin{array}{l}\text { Operated side } \\
\text { Average }-19^{0} \\
\text { Range of } \\
\text { motion }\end{array}$ & $\begin{array}{l}\text { Dorsiflexion } \\
\text { injured side) }\end{array}$ \\
\cline { 2 - 3 } & Plantar flexion & $\begin{array}{l}\text { Average }-25^{0} \\
\text { (compared to } \\
36^{\circ} \text { on the non- } \\
\text { injured side) }\end{array}$ \\
\hline \multirow{2}{*}{ Heel raise } & Sustained present & 20 \\
\cline { 2 - 3 } & <60 second & 8 \\
\cline { 2 - 3 } Neurological & Unable & 3 \\
\hline examination & $\begin{array}{l}\text { Sensory } \\
\text { hypoesthesia in } \\
\text { area distribution of } \\
\text { sural nerve }\end{array}$ & 5 \\
\cline { 2 - 3 } & Normal & 26 \\
\hline
\end{tabular}

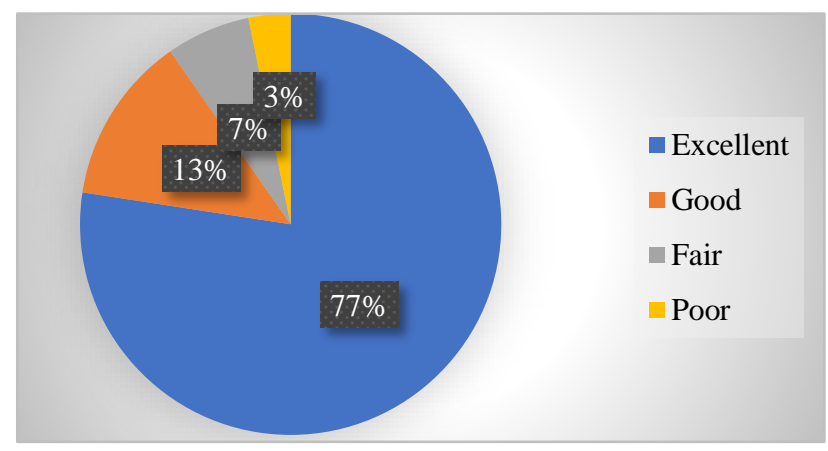

Figure 4: Subjective criteria; modified Rupp score. Results were rated as excellent ( $>30$ points), good (15-30 points), fair (5-15 points) and poor ( $<5$ points).

For Rupp scoring, 77\% patients had excellent or good results and $10 \%$ had fair or poor results.

\section{DISCUSSION}

In total 31 patient's majority of patients belong to 41-50 years $(15$ cases $48.4 \%) .35$ years of age group with maximum ruptures involved in fourth and fifth decade. It is in agreement with $\mathrm{N}$ Vinod Kumar Reddy et al ${ }^{4}$ and also same findings as seen in various other studies. ${ }^{7,8}$ Male patients being $24(77.4 \%)$ constituted the majority. A negative correlation between age and tendinous blood flow was detected for men, which is consistent with previous observations that female gender is a protective factor for Achilles tendon rupture and may also allude the high incidence of Achilles tendon rupture for men in the fourth and fifth decades of their life. ${ }^{9,10}$ These findings may be caused by an increased vascular stiffness, decreased vascular density, or impaired vascular organization, which can lead to a decreased blood supply in aging skin. For that reason, the results of operative treatment of geriatric foot and ankle fractures are essentially determined by the soft tissue management and minimally invasive techniques are recommended in elderly patients. ${ }^{11}$
Right sided injury was noted in 23 (74.2\%) of the patients and left sided in 8 (25.8\%). Similar observations have been found by Chang et al and they have attributed it to more frequent left foot push off with right-hand dominant individuals. $^{12,13}$

Most common symptom of Achilles tendon rupture is pain. Referring to the work of Blazina et al, initially there may be pain in the tendon with the onset of weightbearing activity such as running, but the tendon pain resolves with continued running (the tendon "warms"). ${ }^{14}$ As the Achilles tendinopathy worsens, there may be aching after activity. With increasing use and tendon degeneration the pain may continue during the course of all weightbearing activity and may eventually preclude heavy weightbearing activity due to the level of pain. Morning pain and stiffness is a common feature of Achilles tendinopathy.

Stumble and fall were the common mechanism observed in our study. Sudden forceful dorsiflexion, tendon degeneration, intra-lesional steroid all have been associated with increased ATR. ${ }^{15}$ In our country there is a need to educate farmers and stressing to take proper precautionary measures as used in foreign countries like wearing long boots working in fields rather than working barefooted. Fortunately, the incidence of open Achilles tendon rupture is low in most of the studies despite high preponderance of increasing incidence of violence and road traffic accidents.

In our study Rupp scoring, 77\% patients had excellent or good results and $10 \%$ had fair or poor results. Tawari et al study showed $85 \%$ good or excellent results as per modified Rupp criteria. ${ }^{16}$ Similarly, Teuffer et al reported that this is a dynamic loop repair technique which is biomechanically more sound than static repair. ${ }^{17}$

Maffulli has very rightly advised to individualize the treatment according to concern and health of the patient. ${ }^{18}$ End-to-end repair is possible for gaps of $<2.5 \mathrm{~cm}$ between the divided ends of the tendon. Apart from Achilles tendon itself, Teuffer et al deployed peroneus brevis and Wapner et al used flexor hallucis longus for Achilles tendon repair. ${ }^{19,20}$ Although these were good options, we avoided sacrificing another tendon in an already injured limb because in our opinion by doing so, there may be some functional loss related to transferred tendon. Plantaris tendon is the most useful locally available tendon for further strengthening of Achilles tendon repair and has been advocated for use by surgeons in different ways. In White and Kraynic modification of Teuffer et al technique, they also utilized the plantaris tendon strengthening after repairing the Achilles tendon by bridging the gap with peroneus brevis tendon. ${ }^{21}$ They placed the harvested plantaris tendon on a fascial needle and passed it in a figure of eight manner through the ruptured ends of the tendon. In our described method, we did the darning by previously harvested plantaris tendon-free graft by placing it on fascial needle and passing it spirally through the cut ends of the tendon and tucking it over the repair after applying 
modified Kessler's stitch, without sacrificing peroneus brevis.

Similar augmented techniques are reported in the literature. For instance, Demirel et al noted that primary repair of acute Tendo Achilles rupture augmented with the gastrosoleus turn down flip technique in combination with immediate weightbearing ambulation results in good outcomes overall, but is associated with similar complication rates noted above. ${ }^{22}$

\section{CONCLUSION}

Achilles tendon with the help of peroneus brevis tendon transfer can lead to improved early functional outcome with decreased chances of early disability. Peroneus brevis tendon transfer is an inexpensive and efficient means of reconstruction of ruptured Achilles tendon ruptures in both adults and elderly aged patients. Proper analysis, patient factors, biomechanical restoration of Achilles tendon with peroneus brevis tendon transfer and a well-structured postoperative rehabilitation protocol are the pre- requisites for consistently good results in Achilies tendon ruptures. In conclusion, the techniques described by us are newer and relatively easy ones based on present knowledge of tendon healing and its augmentation which seems to provide a reasonably good outcome.

Funding: No funding sources

Conflict of interest: None declared

Ethical approval: The study was approved by the institutional ethics committee

\section{REFERENCES}

1. Kujala UM, Sarna S, Kaprio J. Cumulative incidence of Achilles tendon rupture and tendinopathy in male former elite athletes. Clin J Sport Med. 2005;15:1335.

2. Jiang N, Wang B, Chen A, Dong F, Yu B. Operative vs nonoperative treatment for acute Achilles tendon rupture: a meta-analysis based on current evidence. Int Orthop. 2012;36:765-73.

3. Kakiuchi M. A combined open and percutaneous technique for repair of Tendo Achilles. Comparison with open repair. J Bone Joint Surg. 1995;7:60-3.

4. Lo IK, Kirley A, Nonweiler B. Operative versus nonoperative treatment of acute Achilles tendon ruptures: a quantitative review. Clin J Sports Med. 1997;7:207-11.

5. Kerkhoffs GM, Struijs PA, Raaymakers EI, Marti RK. Functional treatment after surgical repair of acute Achilles tendon rupture: wrap vs walking cast. Arch Orthop Trauma Surg. 2002;122(2):102-5.

6. Reddy NVK, Reddy PLN. Reconstruction of ruptured Archilles tendon using peroneus brevis tendon transfer to OS calcis. Int J Orthop Sci. 2018;4(2):177-82.
7. Boyden EM, Kitaoka HB, Cahalan TO, An KN. Late versus early repair of Achilles tendon rupture. Clinical and biomechanical evaluation. Clin Orthop Relat Res. 1995;317:150-8.

8. Carden DO, Noble J, Chalmers J, Lunn P, Ellis J. Rupture of the calcaneal tendon. The early and late management. J Bone Joint Surg Br. 1987;69:416-20.

9. Vosseller JT, Ellis SJ, Levine DS, Kennedy JG, Elliott AJ, Deland JT, et al. Achilles tendon rupture in women. Foot Ankle Int. 2013;34(1):49-53.

10. Hess GW. Achilles tendon rupture: a review of etiology, population, anatomy, risk factors, and injury prevention. Foot Ankle Spec. 2010;3(1):2932.

11. Bentov I, Reed MJ. The effect of aging on the cutaneous microvasculature. Microvasc Res. 2015;100:25-31.

12. Chang HJ, Burke AE, Glass RM. Patient page, Achilles tendinopathy. JAMA. 2010;303:188.

13. Singh R, Manoharan G, Moores TS, Patel A. Nintendo Wii related Achilles tendon rupture:first reported case and literature review of motion sensing video game injuries. BMJ Case Rep. 2014;2014:2013202657.

14. Fox JM, Blazina ME, Jobe FW, Kerlan RK, Carter VS, Shields CL, et al. Degeneration and rupture of the Achilles tendon. Clin Orthop Relat Res. 1975;107:221-4.

15. Nagakiran KV, Soraganvi P, Uma MA, Sudeep PM, Bharadwaj MSC. An analysis of functional outcome following tendon augmentation surgeries in patients presenting with steroid-induced tendo achilles rupture and spontaneous tendo achilles ruptures. Indian J Orthop Surg. 2018;4(4):394-401.

16. Tawari AA, Dhamangaonkar AA, Goregaonkar AB, Chhapan JB. Augmented repair of degenerative tears of Tendo Achilles using peroneus brevis tendon: early results. Malays Orthop J. 2013;7(1):19-24.

17. Teuffer PA. Traumatic rupture of the Achilles Tendon. Reconstruction by transplant and graft using the lateral peroneus brevis. Orthop Clin North Am. 1974;5(1):89-93.

18. Maffulli N. Current Concepts Review Management of Chronic Ruptures of the Achilles tendon. J Bone Joint Surg Am. 2008;90:1348-60.

19. Turco V, Spinella AJ. Peroneus brevis transfer for Achilles tendon rupture in athletes. Orthop Rev. 1988; 17:822.

20. Wapner KL, Pavlock GS, Heckt PJ. Repair of chronic Achilles tendon rupture with flexor hallucis longus tendon transfer. Foot Ankle. 1993;14:443.

21. Miskulin M, Miskulin A, Klobucar H, Kuvalja S. Neglected rupture of the Achilles tendon treated with peroneus brevis transfer: a functional assessment of 5 cases. J Foot Ankle Surg. 2005;44(1):49-56.

22. Demirel M, Turhan E, Dereboy F, Yazar T. Augmented repair of acute Tendo Achilles ruptures with gastrosoleus turn down flap. Indian J Orthop. 2011;45(1):45-52.

Cite this article as: Reddy KVB, Lavudi N.

Degenerative tendoachilles tear repaired and augumented by peroneous brevis tendon by dynamic loop technique one year follow up. Int J Res Orthop 2020;6:788-92. 